Edith Cowan University

Research Online

Research outputs 2012

$1-1-2012$

\title{
Posttraumatic stress and posttraumatic growth and their relationship to coping and self-efficacy in Northwest Australian Cyclone communities
}

\author{
Julie Ann Pooley \\ Lynne Cohen \\ Edith Cowan University \\ Moira O'Conner \\ Myra Taylor \\ Edith Cowan University
}

Follow this and additional works at: https://ro.ecu.edu.au/ecuworks2012

Part of the Behavior and Behavior Mechanisms Commons

10.1037/a0028046

This is an Author's Accepted Manuscript of: Pooley, J. , Cohen, L. , O'Connor, M. , O'Conner, M., Taylor, M. F. (2012).

Posttraumatic stress and posttraumatic growth and their relationship to coping and self-efficacy in Northwest Australian Cyclone communities. Psychological Trauma , 5(4), 1-8. Available here (C)American Psychological Association, [2012]. This paper is not the copy of record and may not exactly replicate the authoritative document published in the APA journal. Please do not copy or cite without author's permission.

The final article is available, upon publication, at: [10.1037/a0028046]

This Journal Article is posted at Research Online.

https://ro.ecu.edu.au/ecuworks2012/462 
RUNNING HEAD: Stress and Growth

\begin{abstract}
Posttraumatic Stress and Posttraumatic Growth and their relationship to coping and selfefficacy in Northwest Australian Cyclone Communities
\end{abstract}

Pooley, J.A., Cohen, L., O’Connor, M., \& Taylor, M.

Edith Cowan University

\begin{abstract}
The main focus of disaster research conducted to date has been on providing insights into the negative consequences of experiencing a serious threat or adversity. The present study extends this research endeavour by investigating the positive post-trauma resiliency experiences of 512 survey respondents living in four cyclone prone communities in Northwest Australia. The findings reveal that disaster stress is often accompanied by disaster growth and, thus, provides an alternative resilience-based way of viewing postdisaster interventions.
\end{abstract}


Posttraumatic Stress and Posttraumatic Growth and their relationship to coping and selfefficacy in Northwest Australian Cyclone Communities.

Resilience is a stress-resistant personal quality that allows individuals to cope, adapt and thrive despite an experience of serious threat or adversity (Ahern et al., 2008). Thus, to some measure the resiliency process of struggling to 'bounce back' from challenge and adversity could be construed as being the very grist of the individual/community lifeexperience mill. However, in exceptional circumstances (e.g., following a natural/human initiated disaster) the ability of an individual/community to grieve, struggle, cope accept and ultimately adapt to a new high stress reality goes well beyond their pre-trauma resiliency norm. Indeed, it is this ability to fulfil post-trauma responsibilities and embrace new tasks and experiences that is considered by some to be the very essence of posttraumatic growth (PTG) (Bonanno, 2007).

Three core psychological concepts have been identified within the disaster field of research, namely, stress, coping and self-efficacy, each of which have received varying levels of research attention. Of the three, stress is arguably the most widely researched concept (Ursano et al., 1994). As such, in academia instances of significant psychosocial change (either within the individual or the affected community) are termed stressor events (Van Ameringen et al., 2008). In addition, much research endeavour has been devoted to understanding the human response to post-disaster stressor events within specific age cohorts (e.g., Adult responses see Norris et al., 2008; adolescent responses see Pina et al., 2008; and child responses see Kar, 2009). Consistently, the findings from these studies have suggested that the elderly, adolescents, and children are the most susceptible age groups for developing a high stress response following an experience of an intense stressor (disaster) event (Norris et al., 2008). 
Other sections of academia have focused on understanding the human stress response to post-disaster stressor events within specific groups of adult workers who were either directly or non-directly involved with the disaster. Somewhat predictably individual workers (e.g., response volunteers [Armstrong et al., 1995]; emergency workers [Wagner, McFee, \& Martin, 2009]; nurses and medical workers [Freedy et al., 1992]; emergency managers [Paton \& Flin, 1999]) and the general public who were directly impacted by the disaster were consistently reported as having the greatest post-trauma stress response when compared to their equivalent indirectly involved worker/member of the public (Adams \& Boscarino, 2005). Therefore, the directness of an individual's involvement in a disaster event has been hypothesized to be a key predictor of a posttraumatic stress (PTS) response.

Other researchers still have examined the range of short and long term post-trauma stress responses that humans typically present with following an experience of a disaster event. In this regard, their findings have consistently reported that in the short term individuals experiencing a traumatic event typically manifest signs of demoralization, discontentment, disconnectedness, grief, irritability, fatigue, and loss of concentration (Neria, et al, 2007) while, in the longer term, they typically display aggression, anxiety, delayed onset post-traumatic stress disorder (PTSD), depression, and psychic numbing (Andrews et al., 2007).

The second psychological concept within the field of disaster research to receive considerable research attention is the human coping mechanism. In particular, the research has focused on understanding the types of coping strategies individuals adopt in disaster situations. The consensus being that people generally manifest three distinct types of coping, namely, avoidance coping (i.e., they avoid the issue), emotion coping (i.e., they focus on their emotions), or task-focused coping (i.e., they focus on the task in hand to be solved). Even though the bulk of the coping research relates to adults (e.g., Bachrach \& Zautra, 1985; 
Holaday et al., 1995; Pearlin \& Schooler, 1978), the smaller body of coping research relating to adolescents and children (Ronan \& Johnston, 1999), seems to suggest that the younger the person is at the time of their experience of a disaster event, then the more likely they are to utilize a negative avoidance coping mechanism (Bolin \& Stanford, 1998).

The third psychological concept within the field of disaster research, self-efficacy, has tended to receive far less research attention. This has occured despite Bandura's (2002) hypothesis that self-efficacy is of critical importance to the adaptation and change processes and, therefore, is a crucial component of posttraumatic growth. Indeed, Bandura (1977) has long maintained self-efficacy to be the mediator between knowledge and action, and, furthermore has described self-efficacy as being "people's judgments of their capabilities to organize and execute courses of action required to attain designated types of performances" (Bandura, 1986, p. 391). Further to this Bandura (1995) argues that the development of self efficacy can be understood through mastery. Thus, self-efficacy is thought to tap into a person's appraisal of their ability to act in a given situation regardless of their own skill repertoire (Bachrach \& Zautra, 1985; Rutter, 1985). Moreover, self-efficacy is regarded as being an important moderating and protective motivational construct in disaster situations (Gist \& Mitchell, 1992) as it facilitates coping and provides individuals with a sense of control at a time when their control is often at its lowest ebb (Benight \& Bandura, 2004).

While much of the disaster research conducted to date has focussed primarily on providing insights into the negative consequences of experiencing a serious threat or adversity, Cordova, and colleagues (2001) have argued a need for more specific research to examine the positive post-trauma experiences which sometime occur following a disaster experience. They suggest such research will provide a far fuller picture of what is actually taking place. Support for this contention can be derived from a number of other disasterrelated studies that in the course of reporting their findings have noted positive post-trauma 
experiences in their respective researchcohorts (e.g., women suffering from AIDS see Dunbar et al., 1998; survivors of a ferry disaster see Stephen et al., 1994; combat forces in Vietnam see Fontana \& Rosenheck, 1998; and sexual assault survivor see Frazier et al., 2001). These types of positive experiences are, as already alluded to, the very essence of PTG (McMillen, 1999; Park et al., 1996). PTG is grounded in existential theory (i.e., the re-evaluation of one's life) and is considered by some to be the antithesis of PTS (Cordova et al., 2001; Tedeschi et al., 1998). In one of the most comprehensive models of PTG developed it has been determined that there are 5 dimensions that constitute PTG, these being relating to others; new possibilities; personal strength; spiritual change; and, appreciation of life (Tedeschi \& Calhoun, 1996; Morris, Shakespeare-Finch, Rieck, \& Newbury, 2005). Indeed, PTG has been defined as being a significant and beneficial post-trauma change in the affected individual's cognitive and emotional life that are largely built upon the interrelated constructs of fortitude, hardiness, and self-efficacy (Almedom, 2005).

Given the small but growing research in the PTG resiliency area (Almedom, 2005) the present study has endeavoured to extend the existing knowledge base by reporting on the disaster related stress and PTG experiences of individuals living in Northwest Australian communities who have previously experienced, and continue to live under, threat of seasonal cyclones. Specifically it examines: (1) What are the relationships between individuals' (coping, self efficacy) and disaster experience (stress, growth) variables? (2) What is the best predictor of PTS? (3) What is the best predictor of PTG? (4) What variables differentiate high and low stress groups? Finally, (5) Which variables differentiate high and low PTG groups?

\section{Method}

An accepted measure of PTG was developed by Tedeschi and Calhoun (1996). It measures PTG in individuals based on the different ways they manifest growth, for example, 
perception of self (survivor vs. victim, self reliance vs. vulnerability), interpersonal relationships (self disclosure, emotional expressiveness, compassion, giving to others), and philosophy of life (priorities, appreciation of life, sense of meaning, spiritual development, wisdom). The Posttraumatic Growth Index (PTGI) contains 21 items within 5 subscales measuring in relation to others, new possibilities, personal strength, spiritual change and life appreciation. The PTGI index has been used in individual trauma situations (i.e., diagnoses of cancers/heart attacks, experiences of incest/assaults), where work has been carried out with individuals/communities who have experienced trauma/adversity (Tedeschi et al., 1998). Participants

Participants came from areas in Northwest Australia, which are seasonally threatened and affected by cyclones (Blong, 2003). These areas were identified via the Emergency Management Australia (EMAtrack) database which only recorded events that required federal assistance (over \$10 million AUD) and comprised the communities of Broome, Carnarvon, Exmouth and Kununurra. These four communities had all been affected by cyclone events within the 24 months prior to the study. A survey package containing an information letter, a survey and a post-paid reply envelope was delivered via Australia Post to each residential dwelling in the four communities. In total 512 participants (329 females and 169 males \{14 gender undefined $\}$ ) responded to the survey drop. The respondents ranging in age from 18-81 years (Mean $35.1 \mathrm{yrs}$ ) had lived in their respective communities for periods ranging from 1 month to 60 years (average 3.8 years). Approximately half $(51.17 \%)$ owned their own home. The demographic characteristics are reported for information only and did not form part of the analysis at this time.

\section{Procedure}

Materials 
The focus of the survey was to capture participants' responses to their most recent cyclone event. The study's survey included measures of self-efficacy (SE), coping styles (CS), disaster stress (Impact of Events), and disaster growth (PTGI) and addressed a number of demographic variables including: age, gender, homeownership, residential postcode, and length of residence. The survey's scales are detailed below.

\section{$\underline{\text { Individual Variables }}$}

\section{Self Efficacy $(S E)$}

In this study self-efficacy was measured through the use of Pearlin and Schooler's (1978) seven-item mastery scale designed to ascertain whether individuals regard 'life's chances as being under ones' own control' (p.5). The reported reliability score is .69 (Cronbach's Alpha). For example, "I have little control over the things that happen to me".

\section{Coping Styles (CS)}

Coping style has been long associated with the areas of trauma and disasters. The Coping Style Questionnaire (CSQ) (Carver et al., 1989) contains 30 items that measures three coping dispositions: task focused (TC) (e.g. I concentrate my efforts on doing something about it), emotion focused (EC) (e.g. I put my trust in god), and avoidant coping (AC) (e.g. I refuse to believe that it happened). The CSQ was developed specifically to address selfregulatory functions in coping efforts. The Cronbach's alpha is .78 for the task-focused subscale, .76 for emotion focused, and .77 for the avoidant coping subscale.

\section{$\underline{\text { Disaster Experience Variables }}$}

\section{Posttraumatic Growth Inventory (PTGI)}

This concept of PTG has developed from recognition of the positive impacts of negative events (Tedeschi \& Calhoun, 1996). This 21-item scale is based on five factors (new possibilities, relating to others, personal strength, spiritual change, life appreciation) that can be utilized to determine the ability of individuals to cope after traumatic events (e.g. 
My priorities about what is important in). The reported reliability (Cronbach's Alpha) is .90. life

\section{Impact of Events Scale - Revised (IES-R)}

This scale was developed and utilised clinically and empirically to measure subjective stress to a single traumatic incident. The original IES (Horowitz et al., 1979) was revised in 1996 by Weiss and Marmar to include seven additional items (22-items in total), and another factor (intrusive thoughts and affects, avoidance behaviours and hyperarousal) (e.g. Any reminder brought back feelings about it). The reliability (Cronbach's Alpha and test retest) is reported at .79 to .92 and .89 to .94 , respectively. The reported validity (construct) ranges between .74 to. 87 .

\section{Results}

Reliability testing of each scale used in the survey was performed. Cronbach's Alpha was produced for each scale. The reliability scores ranged from .71 to .96 (see Table 1). This table indicates the reliability statistics of the original studies, from the scales used in the current study. As can be seen the reliability scores are comparable and in five of the six scales scores exceed the original scale reliability. As Groth-Marnet (2008) indicates these alphas are within the acceptable range for research.

\section{INSERT TABLE 1 HERE}

Pearson Correlation coefficients were computed for the scale scores to reveal the relationships between the individual and disaster experience variables. Table 2 indicates the correlations between all scale scores. Examination of scatter plots did not suggest the violation of assumptions of normality, linearity and homoscedasticity for each significant correlation. 
INSERT TABLE 2 HERE

There is a significant moderate relationship between disaster stress and disaster growth in this study, disaster stress significantly and negatively correlates with self-efficacy and the different types of coping all significantly correlate with growth. Disaster stress significantly correlates with avoidant and emotional coping. It is important to note that all of these significant correlations are low to moderate.

$\underline{\text { What predicts Disaster Growth and Disaster Stress? }}$

Residual scatter plots were examined for possible violations of assumptions of normality, linearity, homoscedasticity, and none were evident. Tabachnick and Fidell (2007) indicate that tolerance tests conducted by Statistical Package for the Social Sciences 17.0 (SPSS) protect against the violation of the assumption of multicollinearity.

Standard Multiple Regressions were then performed in order to determine which variables best predict disaster growth (Table 3) and disaster stress (Table 4).

INSERT TABLE 3 HERE

For disaster growth the important variables are disaster stress and emotional coping.

INSERT TABLE 4 HERE

For disaster stress the important variables are disaster growth, self-efficacy and avoidant coping.

What variables differentiate high/low stress groups and high/low growth groups? 
To determine which combinations of variables are predictive of those people that are highly and not highly stressed, discriminant function analyses (DFA) were performed on those that scored in the top $20 \%$ on the IES (High stress group) and those that scored in the bottom $20 \%$ of the IES (low stress group). The determination of percentage chosen for inclusion into high and low stress groups was based on the minimum sample size needed to carry out the DFA. The variables utilized to investigate which factors differentiated those in the high stress group and those in low stress group were SE, CS, PTGI. The data was screened to test the assumptions underlying DFA. Multivariate outliers were assessed using Mahalanobis distance. Although moderate correlations between variables are evident, Tabachnick and Fidell (2007) argue that slight multicollinearity should not present a problem because most DFA programs test for this assumption and exclude variables if the assumption is violated to a great extent. Tabachnick and Fidell (2007) further argue that when sample sizes are equal, robustness of significance tests is expected. In each DFA performed it is important to note that only one function is needed as only two groups are in the analysis (Bishop \& Drew, 1999). The variable Group was used as the dependent variable (i.e., high/low stress).

The correlations among the independent variables ranged from -.280 to .398 . An examination of the canonical discriminant function indicates 1 function, which accounts for $100 \%$ variance and has a canonical correlation of $r=0.544$. The high stress group was found to have lower self-efficacy; used more emotionally focused coping and reported more disaster growth. The low stress group had higher self-efficacy, used less emotionally focused coping and reported less disaster growth. The overall correct classification of cases was $78.7 \%$. The percentage of cases correctly classified in the high stress group was $77.7 \%$ and the low stress group was $81.4 \%$. 


\section{INSERT TABLE 5 HERE}

The high positive growth group was found to have high scores on self-efficacy, emotion focused coping and PTS. The low growth group had low scores on emotion focused coping and PTS and a high score on self-efficacy (see Table 6). The overall correct classification of cases was $79.8 \%$. The percentage of cases correctly classified in the high positive growth group was $86.3 \%$ and the low positive growth group was $72.9 \%$. The correlations among the independent variables ranged from -.280 to .601 .

\section{INSERT TABLE 6 HERE}

\section{Discussion}

The first aim of this study was to determine the relationships between the studied variables in seasonally cyclone affected areas in Northwest Australia. The indications are that there are low to moderate correlations between individual (coping, self-efficacy) and disaster experience (stress, growth) variables in these seasonally cyclone affected areas. The positive relationship between disaster stress and disaster growth (.377) indicates that for residents that experience higher stress are likely to experience higher growth and is in line with other Australian research which posits that an experience of stress can also result in an experience of growth (Shakespeare-Finch \& Morris, 2010; Tedeschi \& Calhoun, 1996; 2004).

Stress appears to relate positively only to avoidant (.186) and emotional (.123) coping where as growth relates positively to all forms of coping $(.199, .115, .278)$. This avoidant coping finding is positively correlated with stress and is consistent with other literature on stress and coping (Stump \& Smith, 2008). With regard to self-efficacy, however, the results show a negative relationship to stress (-.228) indicating the more stress reported, the less self- 
efficacious the residents' report they are, and, thus, is consistent with previous research (Heinrichs et al., 2005).

The study's second aim was to determine which variables best predict disaster stress and disaster growth in this region. For disaster stress the important (significant) variables are self-efficacy, disaster growth, and avoidant coping. However this model only accounted for approximately $23 \%$ of the variance, leaving much of the variation unexplained.

As one of the main symptoms of PTSD is avoidance behavior it is not unreasonable that avoidant coping predicts post-traumatic stress. This result supports previous research, which indicates that self-efficacy plays a significant role in that it is inversely related to disaster stress (Carver et al., 1989; Benight, et al, 1997). Finally, the relationship between disaster growth and disaster stress was foreshadowed in the correlations.

For disaster growth the best predictors are disaster stress and emotion coping. However it is important to note that for posttraumatic growth there is a slight decrease in the variance explained by the regression model (19\%).

The third aim was to determine the variables that influence stress and growth in Northwest Australia. DFA was performed to highlight which variables differentiate residents that obtained high and low stress scores. The discriminating variables were posttraumatic growth, self-efficacy and emotion-focused coping. Results indicate that those residents with a high PTS score, have more PTG $(\bar{x}=49.8)$, use more emotion focused coping mechanisms $(\bar{x}=32.6)$ and are less self-efficacious $(\bar{x}=26.0)$. For those residents that have a low PTS score, they experience less PTG $(\bar{x}=21.7)$, use less emotion focused coping mechanisms $(\bar{x}$ $=26.5)$ and are more self-efficacious $(\bar{x}=29.6)$.

The discriminating variables between residents with high and low PTG scores were PTS, emotion focused coping, and self-efficacy. Residents that scored high on the growth scale also scored high on the stress scale $(\bar{x}=49.8)$, used more emotion focused coping 
mechanisms $(\bar{x}=32.6)$, and were less self-efficacious $(\bar{x}=26.0)$. Residents that scored low on the growth scale scored low on the stress scale $(\bar{x}=21.7)$ and used less emotion focused coping $(\bar{x}=26.5)$.

For the Northwest Australian community the results of the correlations, regressions and DFA present a converging view of the relationships between the study's variables. There is strong evidence to support that PTS and PTG are clearly related to each other in this study. Both the correlations and the DFA indicate the relationship and their role in distinguishing high and low stress and growth groups.

In examining disaster stress in Northwest Australia there are expected markers which distinguish stressed and less stressed residents. In general the mean scores of the participants are lower than other samples which concur with other Australian and international comparisons. For example Creamer, and colleagues (2001) report that even though Australian samples report similar amounts of stress events Australian samples generally report much lower rates of Post-Traumatic Stress Disorder (approx 1.3-1.5\% compared to the US of 3.9\%) (Shakespeare-Lynch \& Morris, 2010). Whilst this current study does not report PTSD it does indicate that levels of stress reported are lower.

A valuable outcome of the current research is the relationship between PTS and PTG. This implies that any understanding of the effect of an adverse experience must take into account the whole experience, disaster stress and disaster growth. In the past much effort has focused on reducing the stress associated with disastrous events, the present results indicate that what accompanies stress is growth. This provides an alternative way of looking at post-disaster intervention. At the individual level, disasters may result in extreme emotional and psychological reactions, which can become dysfunctional, and persist over a long period of time. This research indicates that with the relationship stress has to growth; growth could be a worthwhile focus for post-disaster interventions. Joseph and Linley (2006) 
argue that it is important to consider disaster growth does not imply the absence of disaster stress so any post-disaster work ought to include both disaster stress reduction and a focus on disaster growth.

Another important variable highlighted in this study is self-efficacy. This present study concurs with Bandura (1997) that self efficacy is central to stress reactions. As selfefficacy is an important motivational construct (Gist \& Mitchell, 1992) as in the present study, self-efficacy held a prominent role in reducing stress. Self-efficacy was a significant discriminator for high and low stress groups and for high and low growth groups. In each case the relationship of self-efficacy to stress and growth indicates that the greater the stress or growth the less self-efficacious the residents are. The present result supports Millar et al, (1999) who found that residents under volcanic eruption threat had lower stress scores when their self-efficacy scores were higher. Murphy (1987) argues that individuals who believe in their ability to manage stressful events are less likely to be overwhelmed by a disaster situation. Additionally, it has been argued that self-efficacy is a vitally important mechanisms in the recovery process as over time the impact of acute stress, from a stressor, and it relationship to the development of PTSD is mediated by self-efficacy and can be enhanced through social support (Benight \& Bandura, 2004; Benight \& Harper, 2002; Pooley, Cohen \& O’Connor, 2006: 2010). In regard to the seasonal nature of Northwest Australian cyclones it is important to note that stress from a cyclone event itself is one thing but there is also stress related to the continuing adaptations from cyclone events and the potential for threats each consecutive season.

One of the strongest patterns to emerge from the study is the relationship among the different coping styles. Although the correlations are not high they are significant, suggesting that residents are utilizing several styles of coping. This is indicative of the coping concept where different styles (emotion, avoidant and task) share commonalities. The use of 
the different coping mechanisms may be indicative of the consistency with which rural/remote residents face different adverse events. Stump and Smith (2008) argue that the greater the exposure to trauma the greater likelihood that additional coping mechanisms will be used. Importantly, Zeidner and Saklofske (1996) support that coping styles should be viewed according to their effectiveness in specific situations. The present research results indicate that emotion focused coping featured more strongly than any other coping strategy. Thus, contrary to previous research (Bishop et al., 2000) indicating task-focused coping relates to reduced stress, the present study suggests that in facilitating/alleviating stress or growth interventions emotion focused coping mechanisms should also be considered. Although, critical incident stress debriefing programs have been criticized for their reliance on emotion-focused mechanisms (Moran, 1998). However, it is possibly that these residents are familiar with this type of "debriefing" given they are regularly threatened by cyclones and, therefore, avoidant and emotion focused coping mechanisms may be more salient.

\section{Limitations}

Although the current study does have sufficient participant numbers there are issues with the variables chosen in the analysis and the variance they explain. Therefore there are several possible cautions that need to be considered when viewing the results of the current study. In the first instance although the confirmation of the model of PTG was not a focus of the present paper, there could be some question about the adherence to the PTG model proposed by Tedeschi and Calhoun (1996). Indeed research carried out by Morris, Shakespeare-Finch, Rieck, \& Newbury (2005) confirms the five-factor structure of PTG (by Tedeschi and Calhoun, 1996) within an Australian sample (n=219).

In addition this present study provides a 'retrospective snapshot' of the experience of seasonally affected disaster communities and therefore this area of research would clearly benefit from a longitudinal approach in light of the seasonal cycle of threats and events that 
many communities endure. Clearly advancing our knowledge of stress and growth must go beyond just cross-sectional studies.

Implications

There are a number of implications that emanate from this research. It is not new to argue that recognising strengths within individuals and encouraging positive changes promotes recovery post trauma (Seligman, 1998) however understanding this against a backdrop of seasonal threats and disaster events presents another layer to consider. Interventions within seasonally threatened communities may need to think about the concept of preparedness as part of cyclical/seasonal approach. This would also suggest that psychologists need to be involved in not only interventions but also the development of preparedness programmes to promote positive adaptations in the likelihood of threats and events. The idea of developing "common narratives" (Tedeschi \& McNally, 2011, p. 21) for communities around there experience may be useful in facilitating positive growth.

\section{Summary}

The present study supports stress as an outcome for cyclone communities and also supports PTG as an outcome of seasonal cyclone threats. It is as important to measure growth as it is to measure stress responses to adverse events (Cordova et al., 2001). The present study also establishes Tedeschi and Calhoun's (1996) instrument (PTGI) as a valuable measure of PTG in seasonally threatened communities. The PTGI has previously been utilized to measure PTG within the context of individual trauma events (e.g., heart attacks, cancers, incest). The present study found the PTGI to have good reliability (see table 1) within the framework of a community stressor (cyclones) in Australia. In addition, to utilizing the PTGI, the measurement of PTG in the present study indicates growth is being detected from as little as 4 weeks to 36 months after an event. This supports previous research indicating positive changes can be reported, from adverse events, weeks to years 
after an event (Affleck et al., 1987; Cohen et al., 1998). However, it is also important as highlighted by Joseph and Linley (2006) to recognise the role psychologists and social scientists fulfil in facilitating 'growthful interactions' when dealing with adverse situations at a community level.

Although the current study does have sufficient participant numbers there are issues with the variables chosen in the analysis and the variance they explain. Future research will need to address these issues by including variables that accurately assess the complexity of communities in disaster situations. Future studies need also to ask participants about their actual experience of cyclones and about the level of damage/trauma they experienced. This information will provide greater insight into the relationships noted in this study. Finally, future studies might benefit from adopting a longitudinal design so that judgements can be made about the directionality of variable associations. In addition further work could consider understanding what are the signs or observe possible signs of positive growth after threats or events rather than relying on retrospective accounts. 
References

Adams, R.E, \& Boscarino, J.A. (2005). Differences in mental health outcomes among Whites, African-Americans, and Hispanics following a community disaster. Psychiatry, 68, 250-65.

Affleck, G., Tennet, H., Croog, S. \& Levine, S. (1987). Causal attribution, perceived benefits, and morbidity after a heart attack. Journal of Consulting \& Clinical Psychology, 55, 29-35.

Ahern, N. R., Ark, P., \& Byers, J. (2008). Resilience and coping strategies in adolescents. Paediatric Nursing, 20, 32-36.

Almedom, A.M. (2005). Resilience, hardiness, sense of coherence and posttraumatic growth all paths leading to light at the end of the tunnel. Journal of Loss and Trauma, 10, 253-265.

Andrews, B., Chris, B., Philpott, R., \& Stewart, L. (2007). Delayed-onset Posttraumatic stress disorder. American Journal of Psychiatry, 164, 1319-1326.

Anthony, E.J. (1974). Introduction: the syndrome of the psychologically vulnerable child. In E.J. Anthoy \& C. Koupernik (Eds.). The child in his family: Children at psychiatric risk. (Vol. 3, pp. 3-10). New York: Wiley.

Armstrong, K. R., Lund, P. E., McWright, L. T., \& Tichenor, V. (1995). Multiple stressor debriefing and the American Red Cross. Social Work, 40, 83-90.

Bachrach, K. M., \& Zautra, A. L. (1985). Coping with a community stressor: The threat of a hazardous waste facility. Journal of Health and Social Behavior, 26, 127-141.

Bandura, A. (1977). Self-efficacy: Toward a unifying theory of behavioral change. Psychological Review, 191-215.

Bandura, A. (1986). Self-efficacy. In A. Bandura (Ed.), Social Foundations of Thought and Action (pp. 390-453). Englewood Cliffs, N.J.: Prentice Hall. 
Bandura, A. (1995). Exercise of personal and collective efficacy in changing societies. In A. Bandura (Ed.), Self Efficacy In Changing Societies (pp. 1-45). Cambridge, UK : Cambridge University Press.

Bandura, A. (2002). Growing primacy of human agency in adaptation and change in the electronic era. European Psychologist, 7(1), 2-16.

Benight, C.C., Antoni, M,H., Kilbourn, K., Ironson, G., Kumar, M.A., Fletcher, M.A., Redwine, L., Baum, A., \& Schneiderman, N. (1997).Coping self-efficacy buffers psychological and physiological disturbances in HIV-infected men following a natural disaster. Health Psychology, 6, 248-255.

Benight, C.C \& Bandura, A. (2004). Social cognitive theory of posttraumatic recovery: The role of perceived self-efficacy, Behaviour Research and Therapy, 42, 1129-1148.

Benight, C.C, \& Harper, M.L. (2002). Coping self-efficacy perceptions as a mediator between acute stress response and long-term distress following natural disasters. Journal of Trauma Stress, 15, 177-186.

Bishop, B., \& Drew, N.M. (1999). Multiple discriminant analysis. In S. J. Coakes \& L. G. Steed (Eds.), SPSS Analysis Without Anguish Versions 7.0, 7.5, 8.0. (pp. 225-241). Brisbane: Wiley.

Bishop, B., Paton, D., Syme, G., \& Nancarrow, B. (2000). Coping with environment degradation: Salination as a community stressor. Network, 12, 1-15.

Blong, R. (2003). Development of a National Risk Framework. Paper presented at the Australian Disaster Conference, Canberra.

Bolin, R., \& Stanford, L. (1998). The Northbridge earthquake: Community-based approaches to unmet recovery needs. Disasters, 22, 21-38.

Bonanno, G.A., Galea, S., Bucciarelli, A., \& Vlahov, D. What predicts psychological resilience after disaster? Journal of Consulting and Clinical Psychology, 75, 671-682. 
Carver, C. S., Scheier, M. F., \& \& Weintraub, J. K. (1989). Assessing coping strategies. Journal of Personality \& Social Psychology, 56, 267-283.

Cohen, L. H., Hettler, T. R., \& Pane, N. (1998). Assessment of posttraumatic growth. In R. Tedeschi, C. L. Park \& L. G. \& Calhoun (Eds.), Posttraumatic growth: Positive changes in the aftermath of crisis (pp. 23-42). New Jersey: Lawrence Earlbaum.

Cordova, M. J., Cunningham, L. L., Carlson, C. R., \& Andrykowski, M. A. (2001). Posttraumatic growth following breast cancer. Health Psychology, 20(3), 176-185.

Creamer, M., Burgess, P., \& Mcfarlane, A. C. (2001). Posttraumatic stress disorder: Findings from the Australian national survey of mental health. Psychological Medicine, 31, $1237-1247$.

Dunbar, H. T., Mueller, C. W., Medina, C., \& Wolf, T. (1998). Psychological and spiritual growth in women living with HIV. Social Work, 43, 144-154.

Fontana, A., \& Rosenheck, R. (1998). Psychological benefits and liabilities of traumatic exposure in the war zone. Journal of Traumatic Stress, 11, 485-503.

Frazier, P., Conlon, A., \& Glaser, T. (2001). Positive and negative life changes following sexual assault. Journal of Consulting and Applied Clinical Psychology, 69(6), 10481055.

Freedy, J. R., Shaw, D. L., Jarrell, M. P., \& Masters, C. R. (1992). Towards an understanding of the psychological impact of natural disasters. Journal of Traumatic Stress, 5(3), 441-454.

Gist, M.E., \& Mitchell, T.R. (1992). Self-efficacy: A theoretical analysis of its determinants and malleability. Academy of Management Review, 17, 183-211.

Groth-Marnat, G. (2009). Handbook of Psychological Assessment. (5th ed.). New York: John Wiley \& Sons. 
Heinrichs, M., Wagner, D., Schoch, W., Soravia, L.M., Hellhammer, D.H., \& Ehlert, U. (2005). Predicting posttraumatic stress symptoms from pre-traumatic risk factors. American Journal of Psychiatry, 162, 2276-2286.

Holaday, M., Warren-Miller, G., Smith, A., \& Yost, T. E. (1995). A preliminary investigation of on-the-scene coping mechanisms used by disaster workers. Journal of Mental Health Counseling, 17, 347-359.

Horowitz, M. J., Wilner, N., \& Alvarez, W. (1979). Impact of event scale: A measure of subjective stress. Psychosomatic Medicine, 41, 209-218.

Joseph, S.A., \& Linley, P. A. (2006). Growth following adversity: Theoretical perspectives and implications for clinical practice. Clinical Psychology Review, 26, 1041-1053

Kar, N. (2009). Psychological impact of disasters on children. World Journal of Pediatrics, 5, $5-11$.

Linley, P.A. \& Joseph, S. (2004). Positive change following trauma and adversity. Journal of Traumatic Stress, 17, 11-21.

Luther,S.S. (1999). Poverty and Children's Adjustment. Thousand Oaks, CA:Sage.

Masten, A.S. (2001). Ordinary magic: Resilience processes in development. American Psychologist, 22, 30-37.

Millar, M., Paton, D., \& Johnston, D. (1999). Community vulnerability to volcanic hazard consequences. Disaster Prevention and Management, 8, 255-260.

Moran, C. C. (1998). Individual differences and debriefing effectiveness. The Australasian Journal of Disaster and Trauma Studies, 1, 1-11.

Morris, B. A., Shakespeare-Finch, J., Rieck, M., \& Newbury, J. (2005). Multidimensional nature of posttraumatic growth in an Australian population. Journal of Traumatic Stress, 18, (5), 575-585. 
Murphy, S.A. (1987). Self-efficacy and social support: Mediators of stress on mental health following a natural disaster. Western Journal of Nursing Research, 9(1), 58-73.

Neria, Y., Gross, R., Litz, B., Maguen, S., Insel, B., Seirmarco, G., Rosenfeld, H., Suh, E. J., Kishon, R., Cook, J., \& Marshall, R. D. (2007). Prevalence and psychological correlates of complicated grief among bereaved adults 2.5-3.5 years after September 11th attacks. Journal of Traumatic Stress, 20, 251-262.

Norris, F.H., Stevens, S.P., Pfefferbaum, B., Wyche, K.F., \& Pfefferbaum, R.L. (2008) Community Resilience as a Metaphor, Theory, Set of Capacities, and Strategy for Disaster Readiness. American Journal of Community Psychology, 41, 127-150.

Park, C. L., Cohen, L., \& Murch, R. (1996). Assessment and prediction of stress-related growth. Journal of Personality, 64, 71-105.

Paton, D., \& Flin, R. (1999). Disaster stress: An Emergency management perspective. Disaster Prevention and Management, 8, 261-267.

Pearlin, L. I., \& Schooler, C. (1978). The structure of coping. Journal of Health and Social Behavior, 19, 2-21.

Pina, A.A., Villalta, I.K., Ortiz, C.D., Gottschall, A.C., Costa, N.M., \& Weems, C.F. (2008). Social Support, Discrimination, and Coping as Predictors of Posttraumatic Stress Reactions in Youth Survivors of Hurricane Katrina. Journal of Clinical Child \& Adolescent Psychology, 37, 564- 574.

Pooley, J.A., Cohen, L., \& O’Connor, M. (2006). Community resilience and its link to individual resilience in the disaster experience of cyclone communities in northwest Australia. In D. Paton \& D. Johnston (Eds.), Disaster Resilience. Springfield (pp. 161-173). Illinois: Charles Thomas Publishers.

Pooley, J.A., Cohen, L., \& O’Connor, M. (2010). Bushfire Communities and Resilience: What can they tell us? Australian Journal of Emergency Management, 25(2), 33-39 
Ronan, K. R., \& Johnston, D. M. (1999). Behaviourally-based interventions for children following volcanic eruptions. Disaster Prevention and Management, 8, 169-176.

Rutter, M. (1985). Resilience in the face of adversity: Protective factors and resistance to psychiatric disorder. British Journal of Psychiatry, 147, 598-611.

Rutter, M. (2007). Resilience, competence and coping. Child Abuse and Neglect, 31, 200509.

Shakespeare-Finch, J, E., \& Morris, B.A. (2010). Posttraumatic growth in Australian populations. In Weiss, Tzipi \& Berger, Roni (Eds.) Posttraumatic Growth and Culturally Competent Practice (pp. 157-172). Hoboken, NJ: John Wiley \& Sons.

Stephen, J., Yule, W., \& Williams, R. (1994). The herald of free enterprise disaster: The relationship of intrusion and avoidance to subsequent depression and anxiety. Behaviour Research \& Therapy, 32, 115-117.

Stump, M. J. \& Smith, J. E. (2008). The Relationship between Posttraumatic Growth and Substance Use in Homeless Women with Histories of Traumatic Experience. American Journal on Addictions, 17, 478-487.

Tabachnik, B. G., \& Fidell, L. S. (2009). Using Multivariate Statistics (4th ed.). Boston: Allyn and Bacon.

Taft, C. T., Kaloupek, D. G., Schumm, J. A., Marshall, A. D., Panuzio, J., King, D. W., Daniel W \& Keane, T. M. (2007). Posttraumatic stress disorder symptoms, physiological reactivity, alcohol problems, and aggression among military veterans. Journal Abnormal Psychology, 116, 498- 507.

Tedeschi, R., Park, C.L., \& Calhoun, L. G. (1998). Posttraumatic Growth: Positive Changes in the Aftermath of Crisis (Vol. 9). New Jersey: Lawrence Erlbaum Associates. 
Tedeschi, R.G. \& Calhoun, L.G. (2004). Posttraumatic growth: Conceptual foundation and empirical evidence. Philadelphia, PA: Lawrence Erlbaum Associates.

Tedeschi, R. G., \& Calhoun, L. G. (1996). The Posttraumatic Growth Inventory: Measuring the positive legacy of trauma. Journal of Traumatic Stress, 9, 455-471.

Ursano, R. J., McCaughey, B.G., \& Fullerton, C. S. (1994). Individual and Community Responses to Trauma and Disaster. Cambridge: University Press.

Van Ameringen, M., Mancini, C., Patterson, B., \& Boyle, M.H.(2008). Post-Traumatic Stress Disorder in Canada. CNS Neuroscience \& Therapeutics, 14, 171-181.

Wagner, S.L., McFee, J.A., \& Martin, C.A. (2009). Effects of Traumatic Stress on Firefighters' World Assumptions. Traumatology, 15, 75-84

Weiss, D. S., \& Marmur, C. R. (1997). The impact of event scale - revised. In J. P. Wilson \& T. M. Keane (Eds.), Assessing psychological trauma and PTSD (pp. 399-411). New York: Guilford Press.

Zeidner, M., and Saklofske, D. S. (1996). Adaptive and maladaptive coping. In Zeidner, M., and Endler, N. S. (eds.), Handbook of Coping (pp. 505-531). New York: John Wiley. 
Table 1

Reliability Statistics (Cronbach's Alpha) for each Scale

\begin{tabular}{lllll}
\hline & Original Studies & \multicolumn{2}{l}{ Current Study } & \\
& Scale Alpha & Alpha & Mean & SD \\
\hline Impact of Events & $.79-.94$ & .96 & 14.99 & 17.35 \\
Posttraumatic Growth & .90 & .96 & 33.47 & 25.79 \\
Self Efficacy & .69 & .83 & 28.02 & 5.03 \\
Task Coping & .78 & .87 & 32.52 & 8.48 \\
Emotion Coping & .77 & .79 & 29.16 & 7.47 \\
Avoidant Coping & .76 & .71 & 23.51 & 7.45 \\
\hline
\end{tabular}


Table 2

Pearson Correlations for Each Variable

\begin{tabular}{|c|c|c|c|c|c|c|}
\hline & PTGI & IES & SE & TC & $\mathrm{AC}$ & $\mathrm{EC}$ \\
\hline PTGI & - & $.377 * *$ & -.103 & $.199 * *$ & $.115^{*}$ & $.278 * *$ \\
\hline IES & & - & $-.228 * *$ & .087 & $.186 * *$ & $.123^{*}$ \\
\hline SE & & & - & $.146^{*}$ & $-.280 * *$ & .086 \\
\hline $\mathrm{TC}$ & & & & - & $.132^{*}$ & $.515^{* *}$ \\
\hline $\mathrm{AC}$ & & & & & - & .070 \\
\hline $\mathrm{EC}$ & & & & & & - \\
\hline
\end{tabular}

** Correlation is significant at the 0.01 level (2-tailed).

* Correlation is significant at the 0.05 level (2-tailed).

PTGI Posttraumatic Growth Index; IES Impact of Events; SE Self-Efficacy;

TC Task Focused Coping; AC Avoidant Coping; EC Emotion Focused Coping 
Table 3

Predictors for Disaster Growth

\begin{tabular}{lllll}
\hline Predictors & Beta & $\mathrm{B}$ & $\mathrm{R}$ & $\mathrm{R}^{2}$ \\
\hline Impact of Events & .298 & $.511^{* *}$ & & \\
Self-Efficacy & -.061 & -.315 & & \\
Task Coping & .055 & .156 & .436 & .190 \\
Emotion Coping & .190 & $.652^{*}$ & \\
Avoidant Coping & .061 & .228 & & \\
{$[\mathrm{~F}(5,215)=9.88, \mathrm{p}>.01]$} & & & & \\
\hline$*, \mathrm{p}<.05 ; * *, \mathrm{p}<.01$ & & & &
\end{tabular}


Table 4

Predictors for Disaster Stress

\begin{tabular}{lllll}
\hline Predictors & Beta & $\mathrm{B}$ & $\mathrm{R}$ & $\mathrm{R}^{2}$ \\
\hline Self-Efficacy & -.203 & $-.612^{* *}$ & & \\
Task Coping & .014 & .023 & & \\
Emotion Coping & .109 & .219 & .487 & .237 \\
Avoidant Coping & .188 & $.413^{* *}$ & & \\
Post Traumatic Growth & .218 & $.164 * *$ & & \\
{$[\mathrm{~F}(5,215)=13.05, \mathrm{p}>.01]$} & & & & \\
\hline$*, \mathrm{p}<.05 ; * *, \mathrm{p}<.01$ & & &
\end{tabular}


Table 5

Discriminators for High and Low Impact of Events (IES) Groups

\begin{tabular}{lllll}
\hline Discriminators & Function 1 & $\mathrm{p}$ & Scale M & \\
& Coeff. & & High & Low \\
\hline Posttraumatic Growth & .623 & .000 & 49.8 & 21.7 \\
Self Efficacy & -.553 & .001 & 26.0 & 29.6 \\
Task Coping & -.036 & & & \\
Emotion Coping & .302 & .004 & 32.6 & 26.5 \\
Avoidant Coping & .299 & & & \\
{$\left[\mathrm{x}^{2}(5)=52.750, \mathrm{p}<.000\right]$} & & & \\
\hline $\mathrm{N}=155$ & & &
\end{tabular}


Table 6

Discriminators for High and Low Posttraumatic Growth (PTG) Groups

\begin{tabular}{lllll}
\hline Discriminators & Function 1 & $\mathrm{p}$ & Scale M & \\
& Coeff. & & High & Low \\
\hline Self Efficacy & -.132 & .001 & 26.0 & 29.6 \\
Task Coping & .284 & & & \\
Emotion Coping & .186 & .004 & 32.6 & 26.5 \\
Avoidant Coping & .140 & & & \\
Impact of Events & .827 & .000 & 49.8 & 21.7 \\
{$\left[\mathrm{x}^{2}(5)=49.560, \mathrm{p}<.000\right]$} & & & & \\
\hline $\mathrm{N}=99$ & & & &
\end{tabular}

